DOI: $10.1590 /$ permusi20163508

ARTIGO CIENTÍFICO

\title{
Elgar: o enigma das variações ${ }^{1}$
}

\author{
Elgar: the enigma of the variations
}

\section{Paulo Roberto Peloso Augusto}

Universidade Federal do Rio de Janeiro, RJ, Brasil.

paulopeloso@yahoo.com

Resumo: Reflexões analíticas sobre como as Variações Enigma de Edward Elgar inseremse no epicentro de uma das técnicas mais instigantes da composição musical. A partir de uma abordagem plural, discutem-se aspectos importantes de harmonia, análise, história da música e história da arte. No âmbito do gênero das variações com caráter de desenvolvimento, o criptograma manifesto pelo próprio compositor recebe aqui uma sugestão inédita para sua solução.

Palavras-chave: Variações Enigma de Edward Elgar; análise musical e criptograma; música inglesa sinfônica.

Abstract: Analytical reflections on how Edward Elgar's Enigma Variations fit into the epicenter of one of the most exciting techniques of musical composition. Departing from a plural approach, it discusses important aspects of harmony, analysis, music history and art history. In the context of theme and variations genre with developmental character, the cryptogram manifest by the composer himself receives here a novel suggestion for a solution.

Keywords: Enigma Variations by Edward Elgar; cryptogram in music; symphonic English music.

Data de recebimento: $12 / 12 / 2015$

Data de aprovação final: 15/04/2016

\footnotetext{
1 Este artigo é parte substancial da conferência submetida à Escola de Música da Universidade Federal do Rio de Janeiro, como parte dos requisitos exigidos para participar da prova de promoção para professor titular. Proferida em 08/05/2015 (Resolução 08/2014 do Conselho Universitário/UFRJ).
} 
PELOSO AUGUSTO, Paulo Roberto. (2016) Elgar: o enigma das variações. Per Musi. Ed. by Fausto Borém, Eduardo Rosse e Débora Borburema. Belo Horizonte: UFMG, n.35, p.147-178.

\section{1 - Uma proposta de integração interdepartamental}

0 tema da presente conferência emergiu, não só, por causa do caráter instigante, repleto de interesse do assunto em questão, como também, decididamente, pelo desejo de reunir, numa abordagem integrada, aspectos importantes de harmonia, análise, história da música e história da arte, que são minhas áreas de atuação na Escola de Música da UFRJ. Para melhor compreender as Variações Enigma de Elgar, compositor inglês que viveu entre 1857 e 1934, situando-a no contexto em que foi originada, em 1899, seria importante investigar, inicialmente, o gênero variações enquanto forma e suas técnicas ramificadas no âmbito da composição. A linguagem harmônica desempenha papel não menos importante quando se trata de perceber, detalhadamente, a arquitetura de sons que dão arcabouço a esta técnica, cuja primeva origem remonta aos compositores medievais.

O enigma a que se refere o título, tanto das variações quanto o da presente conferência, certamente é um aspecto artístico. Não só nesta composição, como em outras obras musicais, a presença de um enigma tem despertado a atenção de vários estudiosos da música, desejosos de lhes compreender o fundamento, como num criptograma. Certamente, quanto mais complexa for a solução para um enigma de uma obra de arte provocativa, tanto maior será o interesse pela criptografia envolvida.

Como elucidação desta assertiva, menciono a tão especulada e misteriosa epígrafe musical que Beethoven inseriu no início do quarto movimento do Quarteto ${ }^{\circ}{ }^{0} 16$ op. 135 para cordas, finalizado pouco tempo antes de sua morte (KINDERMAN, 1995, p.51). Epigrafou o compositor: "A difícil decisão", que inicia pela pergunta formulada pelo violoncelo e viola, simultaneamente: “Tem que ser assim?", ao que os dois violinos respondem: "Tem que ser assim!” (BEETHOVEN, 1985, p.20). Independente do fato de esta pergunta e resposta, à maneira de um antecedente e um consequente, fornecerem o material temático e subsequente desenvolvimento para este movimento, permanece a questão: a que se 
PELOSO AUGUSTO, Paulo Roberto. (2016) Elgar: o enigma das variações. Per Musi. Ed. by Fausto Borém, Eduardo Rosse e Débora Borburema. Belo Horizonte: UFMG, n.35, p.147-178.

referiria Beethoven, nesta que foi uma de suas últimas obras conclusas? Ao destino implacável? A uma brincadeira entre ele e um devedor, que lhe perguntara se tinha mesmo que pagar?

Está claro que não é a presença do enigma que dá sentido à obra de arte, mas o mesmo, certamente, cria uma grande expectativa em torno da mesma, provocando o processo intelectual de análise da criação, como ferramenta de estudo, que se engaja em novas frentes, como anteriormente fizeram KERMAN (1970), KINDERMAN (1991) e LOCKWOOD (2004), relativamente à obra de Beethoven. Por outro lado, só faz sentido a presença de um criptograma, se o conteúdo artístico-musical em que o mesmo está imerso estiver bem associado a uma proposta textural, formal e harmônica consistentes.

\section{2 - Presença do gênero variação na história da música}

Considerando, inicialmente, variação como a arte de comentar repetidamente uma enunciação temática a cada vez de maneira diferente, percebemos, no decorrer da história da música, o surgimento e a transformação de técnicas as mais complexas envolvendo possibilidades de variações.

Somos remetidos, por exemplo, à época de Antonio de Cabezón, compositor espanhol que se destacou, em especial, nesta proposta compositiva, na primeira metade do século XVI. Formas por ele consolidadas, os tientos, glosados e principalmente as diferencias, transformaram-se, no âmbito da música instrumental em referências, influenciando compositores, que se lhe seguiram (NELSON, 1962, p.8). Em especial, as concepções da arte de variar mais empregadas, ou seja, com cesura entre uma variação e a seguinte, tornaram-se características por facilmente permitir a identificação individual no referencial de uma sequência de variações, em geral numeradas. 
PELOSO AUGUSTO, Paulo Roberto. (2016) Elgar: o enigma das variações. Per Musi. Ed. by Fausto Borém, Eduardo Rosse e Débora Borburema. Belo Horizonte: UFMG, n.35, p.147-178.

Favorecendo a arte da improvisação, tão cara aos compositores barrocos, privilegiadamente, despontaram recorrentemente as chaconas, passacalhas e, sobretudo, o basso ostinato e é claro, posteriormente, as sonatas.

Dentre a extensa amostragem de coleções de variações barrocas e clássicas basilares, podemos destacar as Variações Goldberg de Bach, com cesuras entre as trinta variações e cujo baixo se apresenta à maneira de uma chacona (SCHULENBERG, 2006, p.369). Também as 33 Variações sobre um tema de Diabelli de Beethoven, que a tantos impressionou por sua ousadia, como a SCHOENBERG $(1969$, p.91), e, segundo Alfred Brendel, "O tema, em vez de ser confirmado, adornado e glorificado, foi melhorado, parodiado, ridicularizado, transfigurado, erradicado e, finalmente sobrevalorizado" (BRENDEL, 2001, p.114).

Até o século XVIII, o processo de variação atuava, preferentemente, na linha melódica, no acompanhamento, na harmonia, na textura, em criação de linhas polifônicas e imitativas. As chamadas variações ampliadoras, que, por vezes, aumentavam consideravelmente o número de compassos em relação ao tema original, também ganharam progressivamente mais espaço nos conjuntos de variações, na passagem para o século XIX. Variações no caráter do tema, levando em conta as flutuações entre o modo maior e o modo menor, assim como variações atuando na dinâmica e na agógica, não esquecendo as flutuações nas alterações de compassos, gerando ritmos dançantes tão diversos, nos dão conta de que antes da era romântica não havia aspecto na arte de variar que não tivesse ainda provocado interesse. E assim, justamente, surgido como uma conquista, pela implantação como prática corrente na música durante o romantismo, sedimentou-se, como preferência, o caráter cíclico das composições. Os que se autoproclamavam compositores da "música do futuro" (ZAMACOIS, 1983, p.216), que, em sua maioria, não eram afeitos à manutenção da sobrevivência do passado musical clássico, como Liszt, César Franck e Wagner, entre outros, acabariam, consequentemente, por revolucionar o conceito de variação, até então vigente. 
PELOSO AUGUSTO, Paulo Roberto. (2016) Elgar: o enigma das variações. Per Musi. Ed. by Fausto Borém, Eduardo Rosse e Débora Borburema. Belo Horizonte: UFMG, n.35, p.147-178.

Um objetivo implícito das formas cíclicas é, justamente, evitar a fragmentação do discurso musical, compelindo-o a uma unidade narrativa mais coesa. Além disso, favorece com este procedimento, que o material temático, que dá origem a composição, em geral resumido, seja explorado o mais intensamente possível. Em síntese, as técnicas de ampliação desempenham um papel tão vital neste tipo de composição, como, por exemplo, na sonata cíclica, que vão favorecer a expansão, em todos os sentidos, da técnica do desenvolvimento musical. Este passa a ocupar lugar de primeira ordem na elaboração da música e será aclamado, juntamente com a variação, como dois dos principais fundamentos da arte de compor.

\section{3 - Variações com caráter de desenvolvimento}

Se tomarmos, por exemplo, as Variações Sinfônicas para piano e orquestra de César Franck, compostas em 1885, observaremos o que Robert NELSON (1962, p.112) chamou de variações livres, já que as cesuras cadenciadas não estão mais presentes. Indicações na partitura prenunciam o início de algumas variações, porém fica evidente a integração contínua entre as mesmas, pela ausência de fragmentação, que até então pulverizava este tipo de composição (DAHLHAUS, 1988, p.5). Entretanto, e eis aí algo digno de nota, ocorre a ausência do entendimento temporal da variação no sentido linear, em relação à construção do tema principal como um todo, incorporando, até mesmo, um caráter "rapsódico", revestindo-se as variações de uma configuração formal própria de um “desenvolvimento livre" (NELSON, 1962, p.119). Ou seja, para além de variar o tema proposto, Franck preocupou-se em desenvolver certos motivos impactantes do tema em si, associando fluentemente à técnica da variação a do desenvolvimento.

A estruturação do desenvolvimento, que durante o classicismo ocupara um lugar equilibrado, em especial, na Forma Sonata, passou, tempestivamente, no dionisíaco século 
PELOSO AUGUSTO, Paulo Roberto. (2016) Elgar: o enigma das variações. Per Musi. Ed. by Fausto Borém, Eduardo Rosse e Débora Borburema. Belo Horizonte: UFMG, n.35, p.147-178.

$\mathrm{XIX},^{2}$ a desempenhar o papel predominante nas composições, em especial naquelas com caráter cíclico. Se, em acréscimo, a estas formas cíclicas o compositor impregnasse o caráter programático, tão caro à estética romântica, que se nutria das fontes poéticas, a possibilidade de redimensionar as combinações estruturais da música seria, então, imprevisível. A palavra de ordem a partir do último quartel do século XIX, em matéria de variações com caráter de desenvolvimento, passou a ser a economia de ideias temáticas, a partir do motivo gerador, pretendendo extrair o máximo possível de resultados na criação de variações, com o mínimo de recursos previamente oferecidos.

\section{4 - Enigmas e criptogramas musicais em voga ao tempo de Elgar}

Acrescentamos, por oportuno, um outro aspecto de grande relevância que nos conduzirá igualmente à compreensão do contexto no qual as Variações Enigma de Elgar estavam imersas. Uma aproximação da natureza dos criptogramas musicais, cujos mistérios poderiam ter seduzido Elgar no transcurso do século XIX, nos permitirá, quiçá, lançar uma luz na questão que contextualizou o enigma, tão excitante nesta composição.

Inicialmente, um tipo de criptograma que se tornou o mais recorrente na música desde o final da Idade Média, foi o que imaginou associar as letras de nomes a notas musicais (NOTATION, 1980, p.348). Entretanto, seria necessário aguardar o período barroco, para que tal procedimento recorrente se transformasse numa prática reconhecida entre os

\footnotetext{
2 Entretanto seria interessante, para nosso objetivo, recordar variações sobre temas, que apresentam simultaneamente as características clássicas e românticas, do livre desenvolvimento. Nas 25 Variações e Fuga sobre um Tema de Händel op. 24, compostas por Brahms, em 1861, notam-se perfeitamente as cesuras, à maneira clássica, separando variações, que são numeradas. Contudo está presente com intensidade a técnica do desenvolvimento livre, a que podemos também nos referir como variações com caráter de desenvolvimento. Comentário similar podemos inferir ao analisarmos as Variações sobre um tema de Johann Sebastian Bach, op. 81 (1904), de Max Reger, que tomou por paradigma a proposta formal concebida por Brahms, mas aprofundou intensamente a técnica da variação com caráter de desenvolvimento (FRISCH, 1984, p.24).
} 
PELOSO AUGUSTO, Paulo Roberto. (2016) Elgar: o enigma das variações. Per Musi. Ed. by Fausto Borém, Eduardo Rosse e Débora Borburema. Belo Horizonte: UFMG, n.35, p.147-178.

compositores. Da mesma forma, a partir da segunda metade do século XIX, houve um ressurgimento desta curiosa e oculta maneira de compor.

Zarlino, na obra Le Istitutioni Harmoniche de 1558, afirma que Josquin des Prez na Missa Hercules Dux Ferrariae de 1503, associou cada vogal deste nome a uma nota musical, através do processo de solmização, ação que o teórico renascentista chamou de "tema extraído das vogais destas palavras" (NOTATION, 2001, p.349). Quando, porém, os criptogramas passaram a envolver nomes com letras do alfabeto restante, que escapavam à simples escala diatônica de A a G (Lá a Sol) e suas oitavas correspondentes, surgiram duas soluções diferentes, em especial, conhecidas como métodos alemão e francês, que acenderam acalorados debates acerca de qual seria o mais pertinente. 0 despeito francogermânico fora espevitado no cenário sombrio às vésperas da Primeira Guerra Mundial. Coube, entretanto, ao método francês, de criptografar nomes em música, consolidado no final do século XIX por Saint-Saëns, fomentar e ampliar o leque de possibilidades para o emprego dos diversos nomes em música.

A seguir, mencionamos três exemplos de criptogramas. Na Figura 1, observamos o nome BACH em disposição cruciforme.

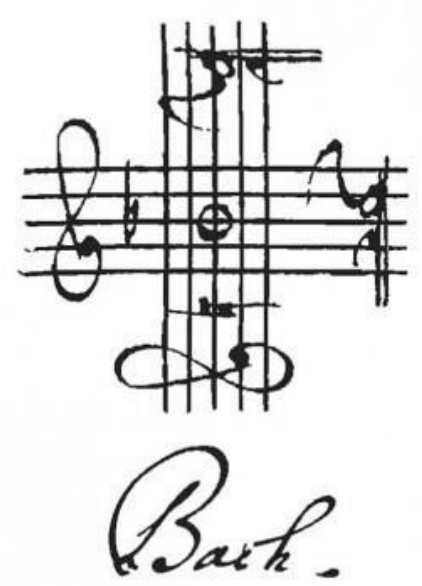

Figura 1: Nome [B - A - C - H] em disposição cruciforme. 
PELOSO AUGUSTO, Paulo Roberto. (2016) Elgar: o enigma das variações. Per Musi. Ed. by Fausto Borém, Eduardo Rosse e Débora Borburema. Belo Horizonte: UFMG, n.35, p.147-178.

Na Figura 2, estão relacionadas as "esfinges" que são a origem temática do Carnaval Op. 9 de Schumann.

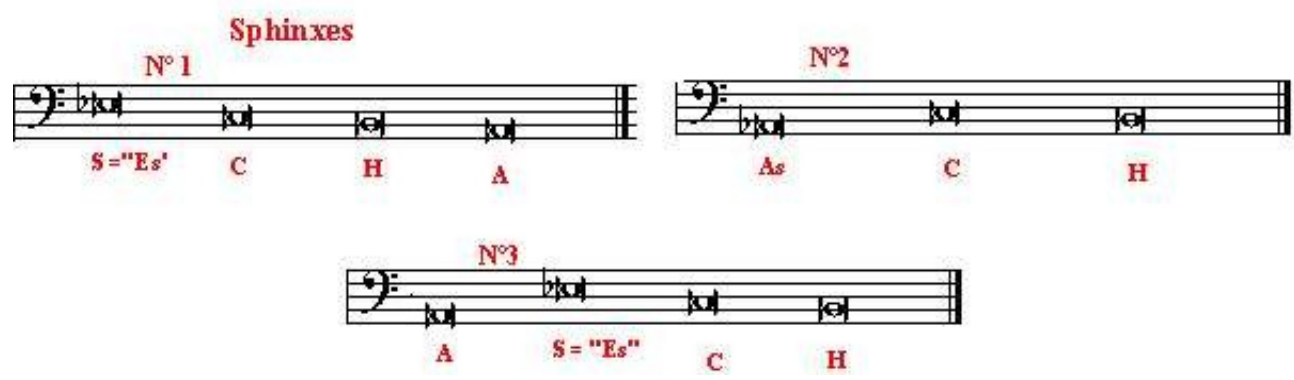

Figura 2: Esfinges [S - C - H - A] e [A - S - C - H] no Carnaval Op. 9 de Schumann.

A figura 3 ilustra o emprego das letras musicais ASCHBEG contidos no sobrenome de Arnold Schoenberg, utilizadas pelo próprio compositor no seu Klavierstück Op. $19 n^{\circ} 1$.

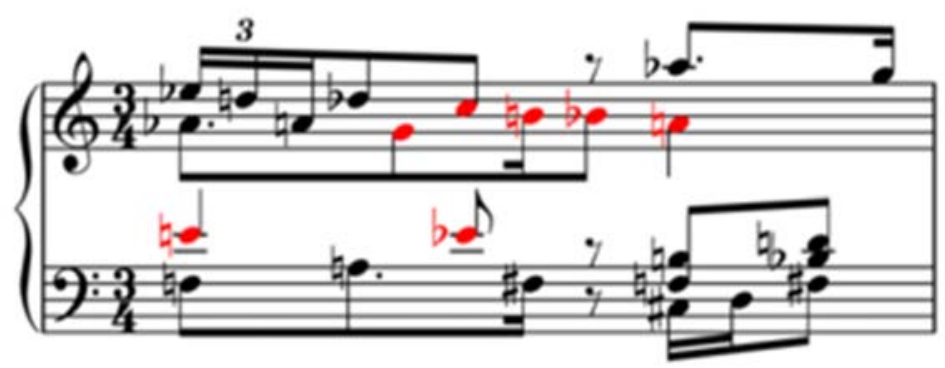

Figura 3: 0 Nome de Schoenberg criptografado [A - S - C - H - B - E - G] no seu Klavierstück Op. 19 no 1.

Já a tabela da Figura 4 demonstra a versatilidade e praticidade francesa para criptografar nomes em música neste modelo adotado no séc. XIX. 
PELOSO AUGUSTO, Paulo Roberto. (2016) Elgar: o enigma das variações. Per Musi. Ed. by Fausto Borém, Eduardo Rosse e Débora Borburema. Belo Horizonte: UFMG, n.35, p.147-178.

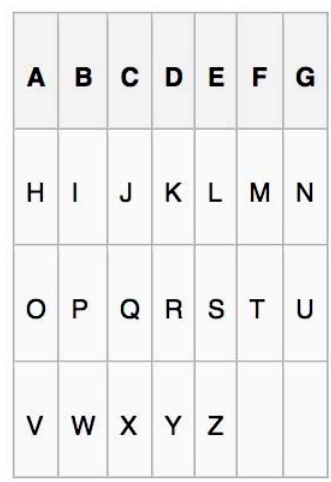

Figura 4: Tabela de método francês de criptografia musical no séc. XIX.

\section{5 - "A música é uma matemática misteriosa”}

Como nos lembra DEBUSSY (1903, p.1) na frase acima, é importante frisar que os criptogramas musicais não se limitam a associar letras, nomes aos sons e mensagens ocultas cifradas. A partir do século XV, a composição musical incrementou uma excitante aproximação centrada na dimensão matemática, que, aliás, vem a ser arcabouço da música. A memória sempre celebra que desde Pitágoras e a teoria musical da Grécia Clássica, a relação entre números e sons, não só acústica, tem sido uma constante durante a história. ${ }^{3}$ Durante a Idade Média, a música integrava os quatro "saberes exatos" do Quadrivium ao lado da aritmética, da geometria e da astronomia, em sintonia com a condição de disciplina matemática, como então era entendida. Além da dimensão teórica e acústica, a prática musical também incrementou procedimentos matemáticos na composição.

Entretanto, por constatar uma influência decisiva da música de Bach sobre Elgar e em especial nas Variações Enigma, revelamos que este compositor barroco integrava, desde 1747, a Sociedade de Ciências Musicais, fundada em 1738 (GEIRINGER, 1985, p.104), cujo

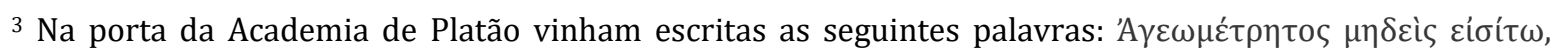
significando "Não deixe nenhum ignorante em geometria entrar" (PAULOS, 1985, p.13).
} 
PELOSO AUGUSTO, Paulo Roberto. (2016) Elgar: o enigma das variações. Per Musi. Ed. by Fausto Borém, Eduardo Rosse e Débora Borburema. Belo Horizonte: UFMG, n.35, p.147-178.

objetivo era estudar as relações entre música e matemática. Para aí ser admitido, compôs um Cânon triplo enigmático a seis vozes BWV 1076, de notória complexidade.

Projetando um olhar em direção à antiguidade clássica, notamos que, sibilinamente, para Vitrúvio (século I A.C.), o arquiteto deveria ter conhecimentos de música para que pudesse entender as leis das proporções matemáticas. Num contraponto arguto, exprimiu-se Goethe: "a arquitetura é uma música petrificada" ao que Xenákis metonimicamente contrapõe: “a música é uma arquitetura móvel” (ZAMACOIS, 1983, p.182).

\section{6 - Um Elgar enigmático}

Associando estas reflexões ao tema ora em tela, vislumbramos o que será apresentado à frente, afirmando que Edward Elgar utilizou não apenas um, mas vários criptogramas em suas Variações Enigma e não só nesta composição, mas em outras de sua autoria (DE-LANOY, 1984, p.55). Em 1897, Elgar enviou uma carta cifrada para Dora Penny, uma das futuras homenageadas nas Variações Enigma. Consiste em um conjunto de oitenta e sete caracteres escritos em três linhas, realizado a partir de um alfabeto de vinte e quatro símbolos, que consistem em um, dois ou três semicírculos, orientados em alguma das oito possíveis direções, com um ponto na terceira linha. Apesar dos esforços, estimulados institucionalmente pela Sociedade Elgar de Londres (THE ELGAR SOCIETY, 2014), que a cada ano promove concursos com o objetivo de se perscrutar o significado deste bizarro texto, nunca se chegou a uma conclusão satisfatória, nem mesmo a própria destinatária, Dora (RILEY, 2007, p.77).

Alhures, após Elgar ter destruído, insatisfeito, o manuscrito de seu primeiro concerto para violino, compôs um segundo, que em 1910, Fritz Kreisler estreou-o, pois o mesmo lhe havia sido dedicado pelo autor. Apesar dos esforços para que este violinista gravasse esta obra, coube, na realidade, ao jovem Yehudi Menuhin registrar em disco pela primeira vez este concerto. A partitura desta peça, traz, em espanhol, uma dedicatória enigmática: “Aqui 
PELOSO AUGUSTO, Paulo Roberto. (2016) Elgar: o enigma das variações. Per Musi. Ed. by Fausto Borém, Eduardo Rosse e Débora Borburema. Belo Horizonte: UFMG, n.35, p.147-178.

está encerrada el alma de...", uma citação extraída da novela de Alain-René Lesage. Da mesma forma, esforços foram envidados para se descobrir a quem se referia esta dedicatória, seguida misteriosamente de cinco reticências, e porque logo em espanhol, porém igualmente frustradas as soluções (MENUHIN, 1976, p.85).

\section{7 - Contextualizando Elgar na música inglesa}

O britânico Gustav Holst (1874-1934) exclamou, ao ouvir pela primeira vez as Variações Enigma de Elgar, que "música assim não surgia na Inglaterra desde a morte de Purcell" (RUSHTON, 1999, p.1). É tempo, como se percebe, de situar o enigmático compositor atuante na Inglaterra Vitoriana do final do século XIX. Antes, não obstante, existe um ponto nodal a ser esclarecido, que vem, a ser esta afirmação tão significativa de Holst, pois entre a morte de Purcell e as Variações Enigma haviam se passado trezentos e quatro anos.

Uma breve análise histórica poderá auxiliar a comprovar o por quê desta situação anacrônica. Um recuo no tempo, posto que brevemente, em busca de fundamentação de hipóteses, poderia trazer uma luz sobre o tema. A título de comparação, constata-se que na Alemanha, durante o século XVI, a Reforma Protestante foi catalisadora de processos artístico-culturais florescentes, como a valorização cada vez mais intensa de um nacionalismo embrionário, que iria refletir-se fortemente na música, dando origem, por exemplo, à notável prática do coral luterano. Bach, seria o expoente deste modus faciendi (GROUT e PALISCA, 1988, p.277).

Já na Inglaterra, a Reforma Anglicana resultou reversamente, pois numa reação extremada e imprevisível, houve um tremendo choque entre a severidade da nova religião e as práticas musicais então florescentes, há muito consolidadas, que tanto se destacaram no cenário Continental, levando a uma estagnação da produção musical vocal e instrumental. Seria preciso aguardar o chamado renascimento musical inglês no séc. XIX, impulsionado pela reforma educacional de Gladstone. Esta favoreceria indiscutivelmente a produção 
PELOSO AUGUSTO, Paulo Roberto. (2016) Elgar: o enigma das variações. Per Musi. Ed. by Fausto Borém, Eduardo Rosse e Débora Borburema. Belo Horizonte: UFMG, n.35, p.147-178.

musical, atendendo aos anseios da alta burguesia em ascensão, sequiosa de legitimar-se através de novos símbolos musicais ingleses, para assistir ao surgimento de compositores representativos, genuinamente britânicos (HARPER-SCOTT, 2009, p.42). Em especial, neste momento, destaca-se o compositor das Variações Enigma, Elgar, que representa este novo impulso social, pois sendo oriundo de uma família pobre, filho de um afinador de piano e autodidata, galgou uma colocação respeitável, graças a seus méritos. Era um compositor completamente profissional, não subserviente de outros trabalhos, como era costume em sua época. Não obstante, no início de sua carreira, até 1890, ter desempenhado modestas tarefas públicas, nunca teve um cargo oficial, podendo com isso dedicar-se inteiramente ao seu idealismo musical, reforçado por uma bagagem de técnicas e experiências não comuns na Inglaterra da época (PARROTT, 1971, p.24).

Esta liberdade de expressão, desvinculada de amarras oficiais, permitiu-lhe buscar uma forma de expressão musical com mais liberdade, mais apropriada a sua linguagem. Abriuse, portanto, ao romantismo clássico de Mendelssohn e Brahms, bem como às propostas de Liszt, Wagner e Richard Strauss, como prova seu oratório O sonho de Gerôncio, de 1900, que admirou ao próprio Strauss em Düsseldorf. Da mesma forma, o vigor harmônico do eslavo Dvorak transpareceu, notadamente, sobre seu Concerto para violoncelo (HARPERSCOTT, 2009, p.98).

\section{8 - As Variações Enigma e os enigmas de cada variação}

Contextualizando, então, a inserção de Elgar no panorama do chamado renascimento musical inglês no século XIX, devemos inferir, que foram justamente as Variações Enigma que o alçaram à fama. E um dos índices deste sucesso seria testemunhar que Gustav Mahler se interessou tanto por estas variações para orquestra, que promoveu a estreia das mesmas em Nova Iorque, em 1910 (SIRMAN, 2006, p.32). Reforçando esta auspiciosa constatação, os russos Rimsky-Korsakov, notável orquestrador, e Alexander Glazunov, então diretor do Conservatório de São Petersburgo, promoveram, entusiasticamente, 
PELOSO AUGUSTO, Paulo Roberto. (2016) Elgar: o enigma das variações. Per Musi. Ed. by Fausto Borém, Eduardo Rosse e Débora Borburema. Belo Horizonte: UFMG, n.35, p.147-178.

apresentações destas variações na Rússia. Além destes, entre os seus admiradores encontravam-se Jan Sibelius, o programático Richard Strauss, Vaughan Williams e, na célere linha do tempo, o jovem Igor Stravinsky (YOUNG, 1973, p.23). É preciso saber que esta obra, na origem, foi improvisada ao piano por Elgar, em 21 de outubro de 1898, estando em casa e tendo sua esposa Alice como ouvinte, que admirada estimulou-o para que a mesma fosse escrita. Este logo aceitou a sugestão e no ano seguinte o manuscrito estava nas mãos de seu amigo, Jaeger, da firma Novello, para impressão e, ato contínuo, cativando o público em Worcester sob a batuta de Hans Richter, em 19 de junho de 1899 (RILEY, 2007, p.234). “Aos meus amigos intimamente retratados” (KENT, 2012, p.202). Esta é a dedicatória de Elgar aos personagens que, de maneira enigmática, aparecem citados nas quatorze variações. Dois sucedâneos que surgem, em cada variação, concorrem para aludir a cada amigo, com evidente destaque para sua esposa Alice e o editor Jaeger. Ou seja, um traço em particular da personalidade associado a uma situação vivenciada por Elgar e o retratado, explorando, na orquestra, um aspecto descritivo na música.

\section{1 - 0 Tema original}

O tema das variações (ELGAR, 1899, p.1-3), como um todo, possui dezessete compassos, estruturado como uma pequena forma ternária a b a', com uma barra dupla simples sinalizando o fim do material temático principal ao final do sexto compasso (BARLOW, 1983, p.175), do qual tudo o que vem a seguir é derivado. Existe uma elisão entre o fim da seção a e o início da seção b, quando o acorde comum de Sol Maior dá, ao mesmo tempo, o sabor de uma terminação picarda e o início de uma nova frase no homônimo maior. A partir daí, até o final do tema, há uma exploração, potencialmente rítmica, mas também melódica do motivo gerador, que aparece já no primeiro compasso, no primeiro violino. Os intervalos mais empregados na frase inicial são as terças e as sétimas, que serão exploradas no decorrer da composição. 0 tema apresenta o caráter molto espressivo, no tom de Sol menor, que se alterna com o homônimo maior na seção b. Segundo o próprio 
PELOSO AUGUSTO, Paulo Roberto. (2016) Elgar: o enigma das variações. Per Musi. Ed. by Fausto Borém, Eduardo Rosse e Débora Borburema. Belo Horizonte: UFMG, n.35, p.147-178.

Elgar a introspecção do tema representa "o sentido de solidão do artista" (KENNEDY, 2004, p.44). Por fim, o tema se prolonga em direção à primeira variação, sem uma cesura perceptível, em virtude de dois compassos que desempenham o papel de transição inserida.

\section{2 - As Variações}

Como dito anteriormente, as variações (ELGAR, 1899, p.4-128), em sua grande maioria são separadas por cesuras e bem cadenciadas, obedecem ao plano das variações com caráter de desenvolvimento. 0 emprego do material motívico é muito distinto, tanto rítmica quanto melodicamente, mas recursos como aumentações, diminuições, ampliações, mudança de tons e modulações, inversões, imitações e inserção de segundas melodias contrapontísticas, são frequentes. É de se salientar que o inciso inicial do motivo gerador da obra, integrante do chamado enigma, é de toda a extensão do tema o fragmento mais utilizado, lembrando que em nenhum momento o tema é variado por inteiro, como seria a prática clássica. Curiosamente, os "amigos intimamente representados" são designados, nos subtítulos das variações, através de abreviaturas, ou seja, pelas letras iniciais de seus nomes ou então por codinomes, à guisa de um disfarce (KENT, 2012, p.223).

\section{3 - Variação I “C.A.E."}

Dedicada à sua esposa, Caroline Alice Elgar, que se casou com o compositor contra a vontade do pai, que não aprovava as diferenças religiosas, ela anglicana, ele católico e por causa do futuro pouco promissor, na época, do filho de um afinador de pianos. Os relatos são, entretanto, de um casamento muito bem-sucedido. Esta variação apresenta não só um caráter expressivo, como traz um motivo secundário composto por quatro notas, que representa um assobio lúdico e cúmplice com que Elgar se auto anunciava ao chegar em casa fazendo-se notar por sua esposa. 
PELOSO AUGUSTO, Paulo Roberto. (2016) Elgar: o enigma das variações. Per Musi. Ed. by Fausto Borém, Eduardo Rosse e Débora Borburema. Belo Horizonte: UFMG, n.35, p.147-178.

Segundo sua própria afirmação, “a primeira variação é realmente uma prolongação do tema, que flui romanticamente com delicadas adições. Aqueles que conheceram C.A.E. entenderão esta referência àquela cuja vida era romântica e de delicada inspiração" (DELA-NOY, 1984, p.89).

\section{4 - Variação II "H.D.S-P”}

0 retratado aqui é Hew David Steuart-Powell, que era um conhecido pianista e intérprete de música de câmara. Seu hábito de dedilhar e improvisar, explorando a extensão do teclado, antes de começar qualquer execução, é aqui humoristicamente representado com uma longa sucessão de semicolcheias, sugerindo uma toccata cromática.

\section{5 - Variação III "R.B.T."}

Outro amigo de Elgar, Richard Baxter Townshend, professor de Oxford. A variação procura descrever um homem idoso, com voz grave, mas às vezes com uns agudos de soprano, em falsete. Sua figura excêntrica, de um homem que se servia de um triciclo com sininhos chegando em Oxford para as aulas, despertava a atenção. Ou seja, há uma linha melódica para descrever a voz instável do personagem e outra distinta para figurar seu excêntrico passeio em triciclo. 0 ambiente geral remete ao gosto aristocrático típico da época.

\section{6 - Variação IV “W.M.B.”}

William Meath Baker, fazendeiro em Hasfield, um apreciador de Wagner, que se auto reconhecia como alguém enérgico e ríspido. É a variação mais curta de todas. 
PELOSO AUGUSTO, Paulo Roberto. (2016) Elgar: o enigma das variações. Per Musi. Ed. by Fausto Borém, Eduardo Rosse e Débora Borburema. Belo Horizonte: UFMG, n.35, p.147-178.

\section{7 - Variação V “R.P.A.”}

O pianista amador Richard Penrose Arnold é aqui representado por desenhos melódicos ascendentes e descendentes típicos de rápidas passagens pianísticas. Esta variação não termina por uma cadência, mas se insere na seguinte. Em um esboço referindo-se ao personagem aludido, Elgar anota mais uma enigmática citação: The Importance of being Earnest, comédia de Oscar Wilde, com tradução ambígua em português: A importância de ser Ernesto; ou Honesto, já que se trata de um trocadilho em inglês. De fato, não parece ser uma alusão simpática ao retratado, pois nesta peça Wilde, com humor cáustico, satiriza a sociedade vitoriana, seus preconceitos, sua hipocrisia e seu gosto pelas aparências. Dois rapazes que fingem se chamar Ernesto para conquistar uma moça, que gosta de homens assim chamados, são o pano de fundo para se evidenciar uma elite parasitária, orgulhosa do nada que representa.

\section{8 - Variação VI "YSOBEL"}

Isabel Fitton era uma violista, aluna de Elgar, que aqui é representada por uma frase na viola solista, através de um exercício típico para os principiantes deste instrumento, cuja dificuldade vai aumentando, progressivamente, através de um processo de variação. Notar, entretanto, que o caráter associado à mesma é inegavelmente amoroso. Esta variação, em Dó Maior, traz um contraponto feito à base do inciso inicial do tema principal, enigma.

\section{9 - Variação VII “TROYTE”}

Arthur Troyte Griffith, arquiteto e pintor de personalidade agitada, era um dos amigos mais íntimos de Elgar. Bem ao estilo da música programática, esta variação descreve burlescamente, nos tímpanos e cordas graves, sua total incompetência como pianista 
PELOSO AUGUSTO, Paulo Roberto. (2016) Elgar: o enigma das variações. Per Musi. Ed. by Fausto Borém, Eduardo Rosse e Débora Borburema. Belo Horizonte: UFMG, n.35, p.147-178.

amador. Fragmentos do tema são aí desenvolvidos, com uma vibrante transformação de dinâmica nos metais, para representar uma intensa tempestade que os surpreendeu ao ar livre, forçando-os a buscar abrigo.

\subsection{0 - Variação VIII “W.N.”}

Winifred Norbury era uma das secretárias da Sociedade Filarmônica de Worcester. Nesta variação, a impressão aristocrática oriunda do século XVIII, se contrapõe no final à típica risadinha, que compunha um dos traços da personagem retratada. Uma nota - Sol - faz a ligação entre esta e a próxima variação.

\subsection{1 - Variação IX “NIMROD”}

Talvez seja de todas a variação mais conhecida e expressiva. Nimrod é o codinome do melhor amigo de Elgar, que trabalhava para a casa Editora Novello de Londres. Há uma correlação curiosa associando Nimrod, o caçador rebelde citado no Gênesis e o sobrenome de Augustus Jaeger, que é o representado aqui, pois Jaeger em alemão - Jäger - quer dizer caçador. Mais um enigma, este facilmente decifrável. A história que inspirou esta variação teve uma importância decisiva para a vida artística de Elgar. Em mais de uma ocasião, referiu-se ao fato que, num particular momento de depressão, pensando em abandonar a carreira de compositor, em vista das evidentes dificuldades que a mesma apresentava, recebeu o estímulo decisivo do amigo e editor Jaeger. Insistindo com Elgar, para que não largasse de maneira nenhuma a composição, apesar de todos os revezes; num determinado momento, mencionou Beethoven, a quem não faltaram desgostos, mas sempre compunha cada vez mais e intensamente. Para completar disse: "E é assim que você tem que proceder!" e cantou a melodia inicial do segundo movimento da Sonata Patética de Beethoven (PARROTT, 1971, p.53). Tal impressão exerceu sobre Elgar esta intervenção, que, posteriormente, ao compor a presente variação, aí introduziu logo no início uma ligeira referência à referida melodia de Beethoven. Disse ele a sua amiga 
PELOSO AUGUSTO, Paulo Roberto. (2016) Elgar: o enigma das variações. Per Musi. Ed. by Fausto Borém, Eduardo Rosse e Débora Borburema. Belo Horizonte: UFMG, n.35, p.147-178.

Dorabella: "Não a ouve logo no início? Somente uma dica, não uma citação" (RUSHTON, 1999, p.158). Por isso, chegou-se a acreditar que esta pequena "dica" seria na realidade o enigma central da peça como um todo. Atualmente, esta variação isoladamente é executada no Reino Unido em momentos de grande comoção.

\subsection{2 - Variação X “DORABELLA"}

Este codinome italiano refere-se a Dora Penny, uma amiga de quem o compositor retratou nas madeiras sua insistente gagueira, à maneira de uma paródia, porém carinhosa. Elgar confidenciou-lhe vários detalhes da composição das variações, menos, é claro, do enigma principal. Mas disse-lhe certa vez: "Você ainda não adivinhou? Experimente de novo. Bem, eu estou surpreso. Eu pensei que dentre todas as pessoas você adivinharia." Não quereria dizer com isso que a filha de um clérigo, habituada às citações bíblicas, deveria estar familiarizada com a solução do enigma? (PARROTT, 1971, p.47). Mais à frente retornarei a esta ideia, desenvolvendo-a.

\subsection{3 - Variação XI “G.R.S."}

O perfeccionista George Robert Sinclair, organista da Catedral de Hereford, dispunha de uma técnica extraordinária de pedaleira. Mas ao contrário do que se poderia imaginar, esta variação não se ocupa de órgãos, virtuosismo ou de catedrais, mas sim de um bulldog, cão do organista e que era muito querido por Elgar. Certa vez presenciaram uma cena pitoresca em que o cão caia de um barranco num rio, nadava contra a correnteza e finalmente alcançava a terra firme com evidente satisfação. "Coloque isto em música", disse-lhe Sinclair (RUSHTON, 1999, p.48). Elgar fê-lo nesta variação, onde o tema principal vem transfigurado, dividido em três elementos, com as seguintes representações: no primeiro o bulldog caindo no rio, com o tema precipitando-se descendentemente. No segundo, o cão nada rio acima, cujo agitado movimento é uma citação clara do motivo 
PELOSO AUGUSTO, Paulo Roberto. (2016) Elgar: o enigma das variações. Per Musi. Ed. by Fausto Borém, Eduardo Rosse e Débora Borburema. Belo Horizonte: UFMG, n.35, p.147-178.

inicial do Exercitium para pedaleira em Sol menor (BWV598) de Bach. E no terceiro momento, a chegada feliz do cachorro.

\subsection{4 - Variação XII “B.G.N."}

Outro músico camerista, amigo do compositor. Desta vez Basil George Nevinson, renomado violoncelista, com quem Elgar frequentemente tocava. Assim, decididamente, o violoncelo tem aqui sua predominância. Sem uma pausa de encerramento, o final desta variação attacca a seguinte.

\subsection{5 - Variação XIII (***) Romanza}

Outro enigma de Elgar, qual seria o amigo intimamente retratado nesta variação? Tem um subtítulo sugestivo Romanza, mas afinal a quem se refere? Muito se especulou sobre as probabilidades e possivelmente deve referir-se a uma mulher, dada a indicação da Romanza.

A razão de não revelar o nome talvez se prenda à superstição do número 13, popular na Inglaterra. Mas existem dois outros sinais que mostram tratar-se de uma amiga, realizando uma viagem de navio, talvez de retorno à Inglaterra. Especulou-se também acerca de um amor secreto... A primeira, e muito evidente, é a citação anotada entre aspas pelo próprio Elgar na partitura, que é extraída indubitavelmente da Abertura em Ré Maior op.27 de Mendelssohn, intitulada Mar calmo e viagem próspera (BARLOW, 1983, p.302), na qual o compositor alemão inspirou-se em dois poemas de Goethe para compô-la. O segundo sinal, não tão evidente, mas muito lógico, é o longo e contínuo rufar de tímpanos em $p p p$ que aparece frequentemente nesta $13^{\mathrm{a}}$ variação, que suscita a lembrança do ruído surdo da antiga maquinaria dos navios a vapor. 0 ambiente geral é de grande melancolia (PARROTT, 1971, p.67). 
PELOSO AUGUSTO, Paulo Roberto. (2016) Elgar: o enigma das variações. Per Musi. Ed. by Fausto Borém, Eduardo Rosse e Débora Borburema. Belo Horizonte: UFMG, n.35, p.147-178.

\subsection{6 - Variação XIV “E.D.U.”}

Desta vez, o próprio Elgar vem retratado, utilizando o apelido alemão, com que sua esposa o chamava, Edu (Edoo). A citação motívica do assobio, ouvido na $1^{\text {a }}$ variação é o que o caracteriza musicalmente, mas dois outros trabalhos temáticos são ouvidos com frequência neste finale, que conclui triunfalmente. Certamente a relembrança das variações, que se referem aos dois personagens mais admirados por Elgar, têm presença destacada aqui, a de sua esposa e a do amigo Jaeger. Mas devemos já sublinhar que se tratam de variações destas duas variações, bem como as dos demais amigos, que aparecem em menor grau.

\section{9 - 0 enigma principal e uma proposta de solução}

A partitura autógrafa desta composição traz simplesmente o título de "Variações para Orquestra compostas por Edward Elgar op. 36". Porém, acima do tema inicial, aparece a palavra "Enigma", adicionada a mão, presumivelmente a pedido de Elgar, pelo editor musical Jaeger, o "Nimrod" da variação IX, que trabalhava, como dito, para a Editora Novello de Londres. Nesta localização, o termo “Enigma” não seria o título da composição, mas uma sugestão para o tema, talvez os primeiros compassos. Contudo, na partitura impressa em 1899, que traz o título "Variações sobre um Tema Original”, o termo "Enigma” aparece centralizado, logo abaixo de "Variações", implicando uma forte conexão entre a palavra e a obra por inteiro (ELGAR, 1899, p.1). Uma vez que esta primeira edição tinha completa aprovação de Elgar e ele próprio nunca deixou de estimular as especulações acerca do enigma presente em sua obra, não há razão para negar a presença real de um criptograma, já presente no tema inicial, e que se estende e se conecta por toda a obra.

Certamente, nunca faltaram os céticos, que colocaram em dúvida e negaram a presença de tal enigma, alegando muitas vezes tratar-se de uma trama burlesca por parte do compositor. 
PELOSO AUGUSTO, Paulo Roberto. (2016) Elgar: o enigma das variações. Per Musi. Ed. by Fausto Borém, Eduardo Rosse e Débora Borburema. Belo Horizonte: UFMG, n.35, p.147-178.

A que se aplicaria tal enigma? Assim, é importante saber que toda a discussão oscila em torno do mistério, segundo o qual o tema original, que dá origem às quatorze variações seguintes, é derivado de uma outra música, a qual Elgar nunca revelou a identidade. Podese inferir daí que o tema principal, ele mesmo, poderia ser uma possível variação de uma peça desconhecida, eis então a caracterização do enigma, que é o que finalmente proporei.

Elgar levou para o túmulo a solução deste mistério, porém referiu a Dora Powell, que é retratada na variação $X$, que "é tão conhecida esta melodia, que é extraordinário que ninguém tenha ainda descoberto" (PARROTT, 1971, p.32), reforçando ainda, neste mesmo momento, que o enigma não se tratava de algo extramusical. Isto levou Troyte Griffith, o retratado na sétima variação, a dizer que o tema oculto deveria ser a melodia mais famosa da Inglaterra, ou seja, o God Save the King, ao que Elgar afirmou peremptoriamente: “certamente, não. Mas é extraordinário que ninguém tenha encontrado, ainda" (PARROTT, 1971, p.33). Ou seja, a solução envolveria, aparentemente, uma música que deveria ser conhecida. E os editores da Obra Completa de Elgar sempre opinaram: "o que está oculto é essencialmente musical e não pode ser traduzido em palavras" (PARROTT, 1971, p.33).

Assim, uma legião de admiradores desta peça, matizada por sua ambiguidade oculta, se empenharam desde a estreia da mesma em 1899, até o presente momento, a decifrar qual seria o enigma por trás destas variações. Além do famoso God Save the King, Elgar ainda refutou outras sugestões, tais como Auld Lang Syne, que no Brasil é conhecido como a Valsa da despedida, em versão de 1941 feita por Braguinha. Discordou ainda do Noturno 6º em Sol menor de Chopin. Aliás, sendo este declaradamente seu tom preferido - Sol menor insuflou que se voltassem as atenções para obras de Bach, expressivas, neste mesmo tom. Assim, o Coral para órgão, em Sol menor deste compositor, também não obteve a aprovação de Elgar, enquanto fonte temática, não obstante fosse Bach seu compositor favorito (PARROTT, 1971, p.35).

Inopinadamente, muitas sugestões foram apresentadas, desde a morte de Elgar, em 1934, e, conseguintemente, foram refutadas por suas inconsistências, seja por outros músicos, 
PELOSO AUGUSTO, Paulo Roberto. (2016) Elgar: o enigma das variações. Per Musi. Ed. by Fausto Borém, Eduardo Rosse e Débora Borburema. Belo Horizonte: UFMG, n.35, p.147-178.

associações ou mesmo a Sociedade Elgar de Londres, que se mantém ativa em publicações, mantendo acesa a memória do músico (THE ELGAR SOCIETY).

Entre estas fontes temáticas encontram-se: Una bela serenata da ópera Cosi fan tutte de Mozart; o próprio nome Elgar em música, seguindo os criptogramas anteriormente descritos e transcrito para o tom de Mi menor; um tema extraído da Quarta sinfonia de Brahms; Twinkle, Twinkle, Little Star, que nada mais é do que a versão inglesa da canção francesa Ah vous dirais-je, Maman, que Mozart empregou em suas doze variações; um cânon de Thomas Tallis e, ainda, como já mencionado, as primeiras nove notas da variação Nimrod. Estas sugestões se enquadram na categoria de contraponto, ou seja, a melodia oculta agiria contrapontisticamente com o tema das variações (TURNER, 1999, p.121).

Entretanto, já sem o caráter contrapontístico, outras tantas hipóteses foram aventadas, tais como: a conhecida ária para soprano, que dá conclusão à ópera Dido e Eneas de Purcell; o Agnus Dei da Missa em Si menor de Bach; reiteradamente, o início do segundo movimento da Sonata Patética op.13 de Beethoven; o Contrapunctus XIV da Arte da Fuga de Bach, quando o nome BACH aparece como motivo principal; Rule Britannia!, um dos hinos patrióticos ingleses; Ave Maris Stella de John Dunstable; Quatro canções sérias de Brahms; o Dies Irae do Gradual Gregoriano e a Marcha para o Calvário de Gounod (TURNER, 1999, p.122).

Uma frase de Elgar, entretanto fez com que muitos inferissem uma subserviência extramusical. Disse ele tratar-se de "algo oculto" (BYRON, 2000, p.40), logo poderia ser tanto uma citação bíblica, como foi levantado, como também, polemiza Edmund Green, poderia ser o Soneto 66 de Shakespeare, sendo o termo enigma, na realidade, um disfarce para a Dark Lady dos Sonetos (GREEN, 2004, p.3), musa misteriosa de Shakespeare, cujos Poemas de Amor foram, no Brasil, traduzidos, pela especialista no bardo inglês, Bárbara 
PELOSO AUGUSTO, Paulo Roberto. (2016) Elgar: o enigma das variações. Per Musi. Ed. by Fausto Borém, Eduardo Rosse e Débora Borburema. Belo Horizonte: UFMG, n.35, p.147-178.

Heliodora ${ }^{4}$. Aventou-se a probabilidade de ser também o nome cifrado de sua filha Carice (DE-LA-NOY, 1984, p.50).

Recentemente, a observação de que as primeiras notas do tema enigma são os graus 3 - 1 - 4 - 2 da escala, levantou novamente a perspectiva de um criptograma, em que a base da solução seria a constante matemática $\pi$ [3.14159265358979...] (SANTA, 2010, p.112), mas como é um número irracional, muitos contra argumentaram a arbitrariedade flagrante: por que deveria o número $\pi$ encerrar então no terceiro dígito? Houve ainda quem correlacionasse o enigma destas Variações ao do citado Concerto para violino: "Aqui está encerrada el alma de...", que tem cinco reticências, que bem poderiam ser as cinco letras do nome Elgar e que corresponderia à sugestão enigmática das próprias variações (DELA-NOY, 1984, p.50).

Não passou em desapercebido a tantos, plausivelmente, que tudo não teria passado de um delicioso gracejo, por parte do próprio Elgar, espírito fino e bem-humorado, que quis troçar, quiçá, com os contemporâneos e a posteridade. Certamente, não pertenço a este grupo cético.

Seria interessante recordar o impacto que este enigma exerceu sobre a criação artística e, como exemplo, cito a célebre peça teatral de Éric Emmanuel Schmitt, estreada em 1996 no Théâtre Marigny de Paris, que tem o nome sugestivo de Variations Énigmatiques.

"Quem amamos quando amamos? Saberemos alguma vez quem é o ser amado? 0 amor partilhado não será afinal um feliz mal-entendido?" (ÉRIC-EMMANUEL-SCHMITT, 2014).

Divisamos em torno destes mistérios eternos do sentimento amoroso, dois homens se defrontando: Abel Znorko, Prêmio Nobel de literatura, que vive isolado do mundo numa ilha perdida no mar da Noruega, onde recorda a sua paixão por uma mulher com a qual

\footnotetext{
4 Não tem olhos solares meu amor; Mais rubro que seus lábios é o coral; Se neve é branca, é escura a sua cor; E a cabeleira ao arame é igual. (SHAKESPEARE, 2000, p.32)
} 
PELOSO AUGUSTO, Paulo Roberto. (2016) Elgar: o enigma das variações. Per Musi. Ed. by Fausto Borém, Eduardo Rosse e Débora Borburema. Belo Horizonte: UFMG, n.35, p.147-178.

trocou uma longa correspondência e Erik Larsen, um jornalista que arranjou o pretexto de uma entrevista para se encontrar com o escritor. Mas qual o motivo deste encontro? Qual a ligação secreta entre ele e a mulher pela qual Znorko se diz ainda apaixonado? E porque é que um misantropo como o escritor afinal acedeu em recebê-lo? A música das Variações Enigma de Elgar está presente para, enfaticamente, acentuar o clima de mistério envolvente. 0 elenco de estreia trouxe Alain Delon e Francis Huster como protagonistas e a peça conheceu um período de enorme sucesso em vários países (ÉRIC-EMMANUELSCHMITT, 2014).

\section{0 - Reunindo dados para uma possível solução}

Ao longo desta exposição, não restou dúvida quanto à admiração de Elgar por Johann Sebastian Bach. Em 1850, surgia em Leipzig a Bach-Gesellschaft - Sociedade Bach - com o objetivo de publicar a obra completa deste compositor alemão, que então intitulava-se Bach-Gesellschaft-Ausgabe - Edição da Sociedade Bach. A partir de 1900 esta sociedade era refundada, agora sob o nome de Neue Bachgesellschaft - Nova Sociedade Bach. Elgar, ele próprio, era um pesquisador interessado na coleção completa da obra de Bach, tendo entusiasticamente ofertado esta integral à Universidade de Birmingham, em 1905 (MCVEAGH, 2013, p.79). A variação XI apresenta, inclusive, como já relatado, uma citação temática extraída do Exercitium para pedal BWV598, em Sol menor, de Bach.

É preciso não esquecer o caráter místico de Elgar, que sendo adepto do catolicismo estava igualmente bem entrosado com os praticantes do anglicanismo de sua época, a religião majoritária da Inglaterra, da qual sua esposa Alice era praticante. Também notamos como um traço recorrente do caráter pessoal deste compositor, o gosto pela criptografia, que surge não só em composições distintas, como também em escritos pessoais.

Dirigindo-nos a uma possível interpretação do enigma central das variações, acrescento um outro dado que aqui julgo relevante. Até a implantação da reforma litúrgica que 
PELOSO AUGUSTO, Paulo Roberto. (2016) Elgar: o enigma das variações. Per Musi. Ed. by Fausto Borém, Eduardo Rosse e Débora Borburema. Belo Horizonte: UFMG, n.35, p.147-178.

aconteceu depois do Concílio Vaticano II, dentro do calendário das celebrações, o domingo imediatamente anterior à quarta-feira de cinzas era conhecido como Domingo da Quinquagésima, por estar a cinquenta dias do domingo de Páscoa. Esta celebração coincidia com o Domingo de Carnaval.

Ainda no início da década de 1960, os católicos, anglicanos e luteranos partilhavam no seu calendário litúrgico, entre outras celebrações, a do domingo da Quinquagésima, cujas leituras neste dia eram comuns às três confissões. Sempre causou forte impressão a Elgar um fragmento da primeira leitura da missa deste dia (MESSENGER, 2008, p.132), retirada dos treze versículos iniciais do capítulo XIII, da $1^{\text {a }}$ Epístola de São Paulo aos Coríntios. Assim se lê no versículo 12: "Porque agora vemos por espelho, em enigma, mas então veremos face a face; agora conheço em parte, mas então conhecerei como também sou conhecido" (1 Cor. 13:12). Ora, a palavra-chave do enigma aqui é a palavra grega " $\alpha$ "vı $\gamma \mu \alpha$ ", que pode ser traduzida por "aquilo que dificilmente se compreende".

Logo, por aqui se aduz o por quê de Elgar representar todos os personagens mencionados em suas variações através de procedimentos de intrincada percepção. Possivelmente, ele aplicava as palavras de São Paulo, que tencionam dar sentido a nossa existência repleta de interrogações, aos próprios amigos representados, pois teriam que se auto desvelar, confusamente, em um espelho, como num enigma. Certamente que há nisso um sentido existencial e filosófico, mas é inegável que há, outrossim, uma boa dose de humor nestas charadas musicais. Entretanto, procurando unir estas evidências ora apresentadas, de maneira original, buscando uma interpretação própria sobre qual a origem do tema principal das Variações Enigma, devemos mais uma vez nos referir a Johann Sebastian Bach. Pois este compositor em sua extensa coleção de obras vocais, publicadas na Edição da Sociedade Bach, dedicou nada menos que quatro cantatas ao Domingo da Quinquagésima, também conhecido por Domingo Esto Mihi. Estas duas palavras extraídas da Vulgata, em latim, fazem referência ao princípio do introito deste dia, Esto Mihi in Deum protectorem, que se traduz por "Sê para mim um Deus protetor". Já o texto inicial do 
PELOSO AUGUSTO, Paulo Roberto. (2016) Elgar: o enigma das variações. Per Musi. Ed. by Fausto Borém, Eduardo Rosse e Débora Borburema. Belo Horizonte: UFMG, n.35, p.147-178.

evangelho deste dia, centralizado, em alemão, por Bach no frontispício da cantata e servindo de letra ao movimento introdutório, iniciava com as palavras: "Jesus tomou à parte os doze".

Esta curiosa confluência de dados levou-nos a investigar as quatro cantatas acima referidas, sendo que a de número 22 , apresenta o primeiro movimento justamente no tom preferido de Elgar: Sol menor (BACH, 1992, p.2-3). Deparando-nos com a introdução orquestral deste movimento, cuja orquestração é constituída por oboé, violinos I e II, viola e contínuo (Figura 5), detectei a similaridade numérica entre os sete compassos iniciais do tema de abertura da cantata, que são equivalentes aos da seção inicial do tema das Variações Enigma (Figura 6).

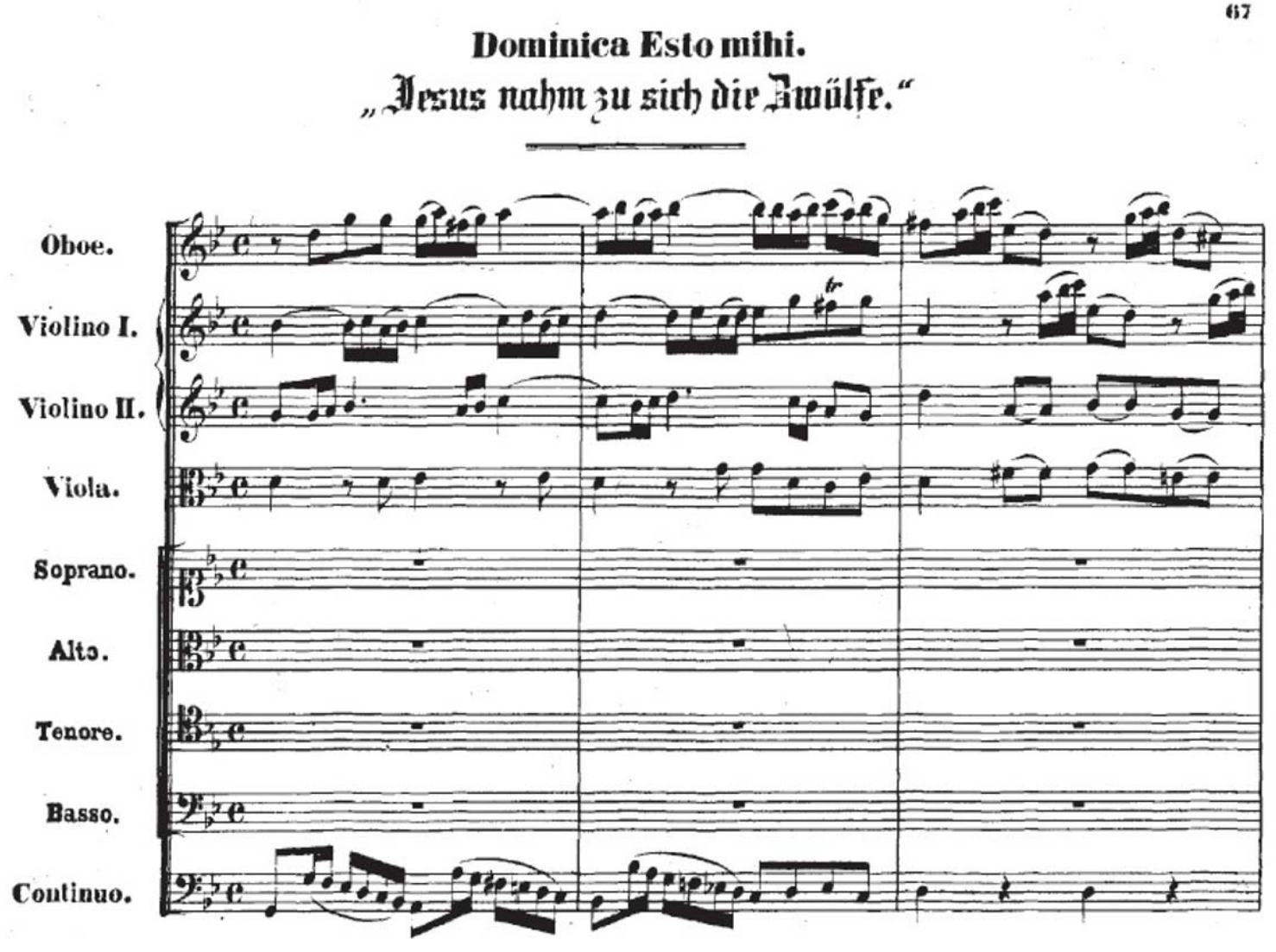

Figura 5 - Início da Cantata Dominica Esto Mihi em Sol Menor de J. S. Bach. 


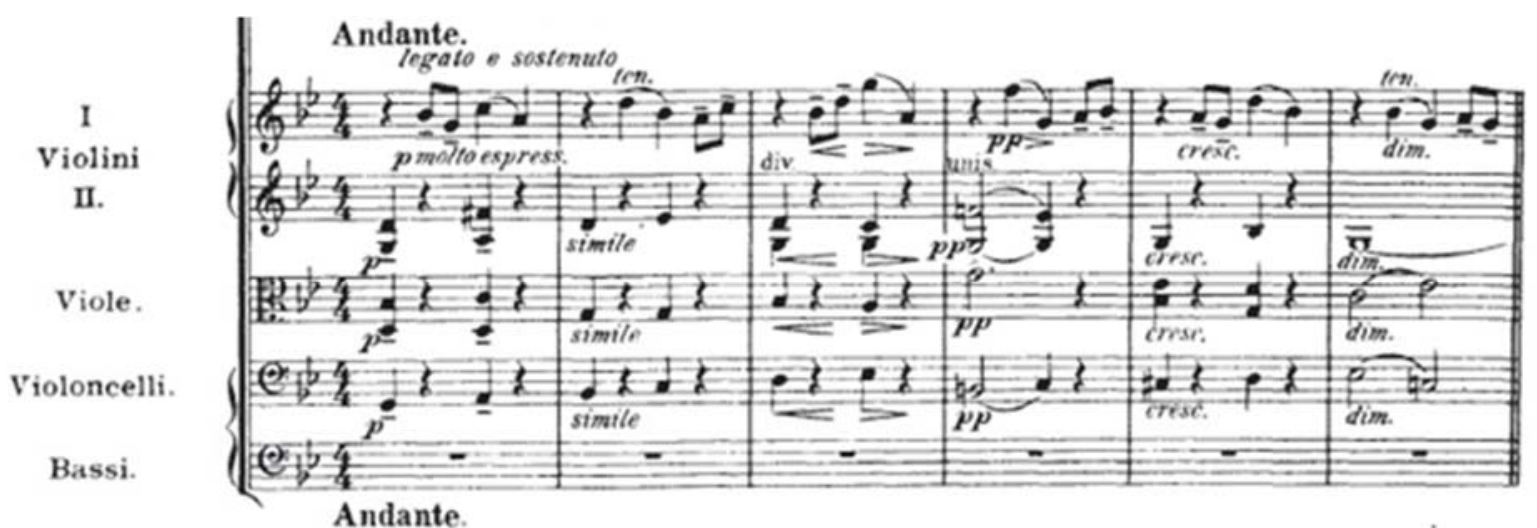

Figura 6 - Início das Variações Enigma em Sol Menor de Edward Elgar.

É realmente muito significativo que este tema esteja em uma relação harmônica correspondente com a frase inicial de Bach, ao mesmo tempo em que se verifica a complexa presença de um contraponto invertível à oitava entre o tema de Elgar e as vozes do oboé, violinos I e II e a viola. Assim, propomos uma escuta da junção da trama contrapontística da cantata de Bach simultaneamente à melodia do tema de Elgar. Sucessivamente, oportunamente recorrendo à característica central do contraponto invertível, substitumos em cada um dos instrumentos citados o enigmático tema (Figura 7). Este exercício gerou uma crescente e gratificante surpresa de notar um perfeito entrosamento das duas obras em vários níveis. Ao final, uma solução para o enigma de Elgar pode ser localizado pelo menos um século e meio antes de sua escrita, em Bach. 
PELOSO AUGUSTO, Paulo Roberto. (2016) Elgar: o enigma das variações. Per Musi. Ed. by Fausto Borém, Eduardo Rosse e Débora Borburema. Belo Horizonte: UFMG, n.35, p.147-178.
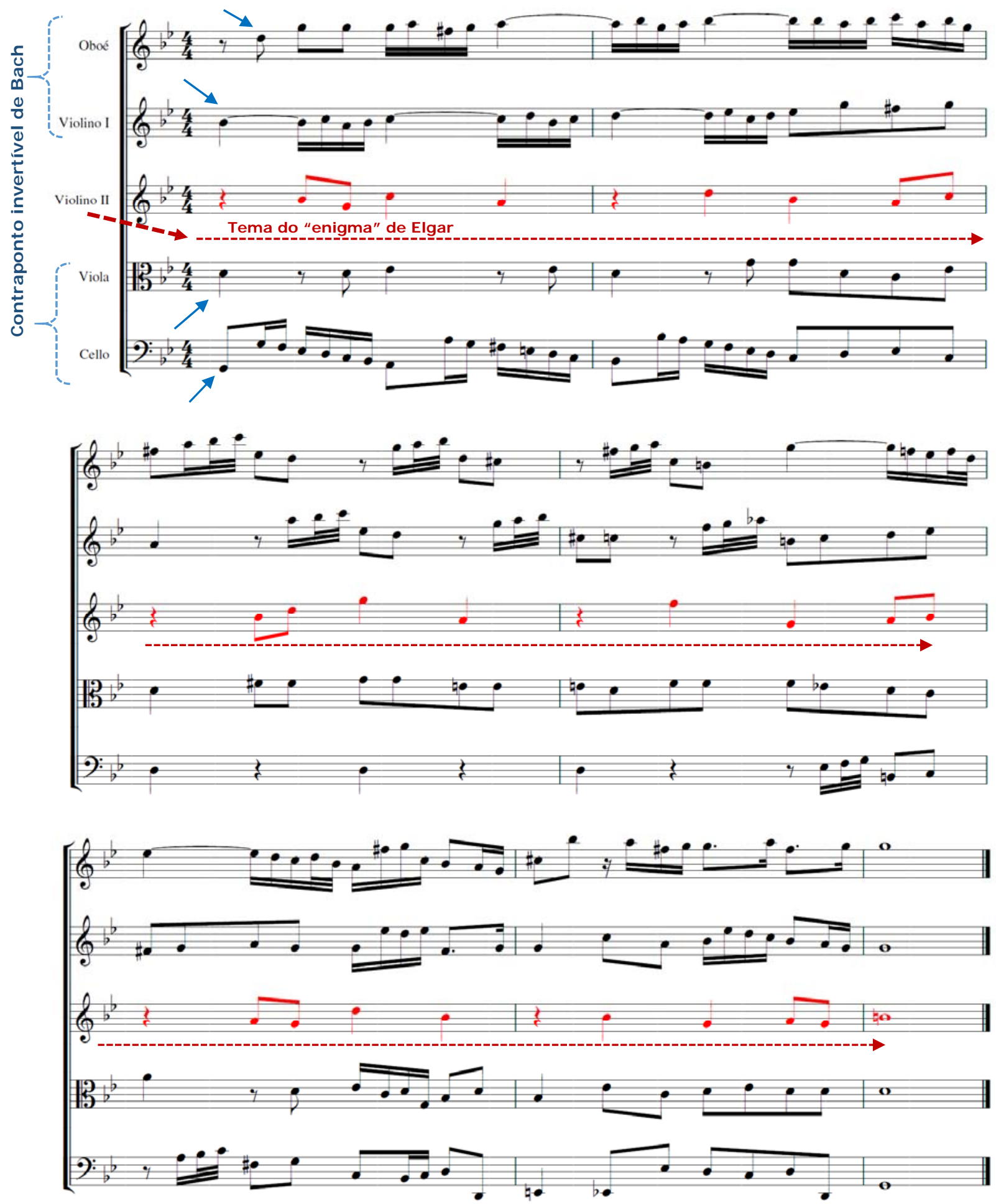

Figura 7 - Uma possível solução para o "enigma" de Elgar: o contraponto invertível de Bach na Cantata Dominica Esto Mihi de J. S. Bach em Sol Menor. 


\section{1 - Considerações finais}

Assim, retornava-nos à lembrança a frase de Elgar, em uma de suas poucas e nada esclarecedoras entrevistas sobre a natureza do enigma: "o tema é um contraponto sobre uma bem conhecida melodia, a qual nunca é ouvida" (TURNER, 1999, p.121). E também: “... Então o tema principal nunca aparece. 0 mesmo acontece em alguns dramas recentes, como por exemplo, $O$ intruso $e$ as sete princesas de Maeterlinck, quando o principal personagem nunca aparece no palco" (MESSENGER, 2008, p.145). Desta maneira, nossa pretensão aqui não foi esgotar a discussão em torno deste assunto palpitante, que nos induziu a fazer tantas abordagens diferentes no decorrer da conferência, para contextualizar absolutamente a problemática pretendida. Não, mais do que uma resposta, ambicionamos exercitar a integração entre as técnicas de variação, linguagem musical, texturas, desenvolvimentos motívicos, criptogramas, bem como a rediscussão de renovadas formas de expressão em cada contexto histórico.

É necessário integrar a música através da história, aproximando-a das demais manifestações artísticas, para que as técnicas de análise se revistam continuamente de um novo sentido. E, certamente, há uma sedução na arte do enigma, pois como disse George Orwell, "se quiser guardar um segredo, terá também que escondê-lo de si próprio" (MOODIE, 2004, p.101).

\section{Referências}

BARLOW, Harold; MORGENSTERN, Sam (1983). A Dictionary of Musical Themes (revised edition). New York: Crown Publishers.

BRAHMS, Johannes (1862). Variationen über ein Thema von Händel, op.24. Leipzig: Breitkopf \& Härtel.

BRENDEL, Alfred (2001). “Beethoven's Diabelli Variations”. In: Alfred Brendel On Music. Chicago: A Capella. 
PELOSO AUGUSTO, Paulo Roberto. (2016) Elgar: o enigma das variações. Per Musi. Ed. by Fausto Borém, Eduardo Rosse e Débora Borburema. Belo Horizonte: UFMG, n.35, p.147-178.

BYRON, Adams (Spring, 2000). "The 'Dark Saying' of the Enigma: Homoeroticism and the Elgarian Paradox”. In: 19th-Century Music, vol. 23, no. 3, p.218-235.

DAHLHAUS, Carl. "What is Developing Variation?". (1988). Schoenberg And The New Music, p.128-133, Cambridge: Cambridge University Press.

DEBUSSY, Claude (Maggio 1903). "Considération sur Prix de Rome au point de vue musical”. In: Musica.

DE-LA-NOY, Michael (1984). Elgar: The Man. London: Penguin Books Ltd.

ÉRIC-EMMANUEL-SCHMITT Disponível em <http://www.eric-emmanuelschmitt.com/Accueil-site-officiel.html> Acesso em: 25 jul. 2014.

FRISCH, Walter (1984). Brahms and the Principle of Developing Variation. Berkeley: University of California Press.

GEIRINGER, Karl (1985). Johann Sebastian Bach. Rio de Janeiro: Jorge Zahar Ed.

GREEN, Edmund (november, 2004). “Elgar's 'Enigma': a Shakespearian solution”. In: Elgar Society Journal. London.

GROUT, Donald; PALISCA, Claude (1988). História da música ocidental. Lisboa: Gradiva.

HARPER-SCOTT, J. P. E. (2009). Edward Elgar, Modernist. Cambridge: Cambridge University Press.

KENNEDY, Michael (2004). The life of Elgar. Cambridge: Cambridge University Press.

KENT, Christopher. (2012). Edward Elgar: A Thematic Catalogue and Reasearch Guide (2 edition). London: Routledge.

KERMAN, Joseph. (1970). Beethoven's early sketches. The Musical Quarterly. Oxford: Oxford University Press, v.56, n.4, p.515-538. Joseph (1969). The Beethoven Quartets. New York: W. W. Norton \& Company.

KINDERMAN, William (1991). Beethoven's Compositional Process. Nebraska: University of Nebraska Press. 
PELOSO AUGUSTO, Paulo Roberto. (2016) Elgar: o enigma das variações. Per Musi. Ed. by Fausto Borém, Eduardo Rosse e Débora Borburema. Belo Horizonte: UFMG, n.35, p.147-178.

William (1995). Beethoven. Oxford: Oxford University Press.

LOCKWOOD, Lewis (2004). Beethoven: a música e a vida. Trad. Lúcia Magalhães e Graziella Somaschini. São Paulo: Codex.

MCVEAGH, Diana (2013). Elgar the Music Maker. Suffolk: Boydell Press.

MENUHIN, Yehudi (1976). Sir Edward Elgar: my Musical Grandfather. London: Elgar Society.

MESSENGER, Michael (2008). Edward Elgar. Oxford: Shire.

MOODIE, Andrew (Nov 2004). "Elgar’s 'Enigma': the solution?". In: Elgar Society Journal. London.

NELSON, Robert U. (1962). The Technique of Variation: A Study of the Instrumental variation from Antonio de Cabezón to Max Reger. Berkeley and Los Angeles: University of California Press.

NOTATION (2001). In: SADIE, Stanley (ed.). The New Grove Dictionary of Music and Musicians. Vol. 13. 2nd Edition. London: Macmillian, p.348-349.

PARROTT, Ian (1971). Elgar. London: J. M. Dent and Sons LTD.

PAULOS, John Allen. (1995). A Mathematician Reads the Newspaper. New York: Anchor Books.

RILEY, Matthew (2007). Edward Elgar and the Nostalgic Imagination. Cambridge: Cambridge University Press.

RUSHTON, Julian (1999). Elgar: 'Enigma' Variations. London: Cambridge University Press.

SANTA, Charles Richard (Spring, 2010). Solving Elgar's Enigma. In: Current Musicology. Columbia. p.112-120.

SCHULENBERG, David (2006). The Goldberg Variations. Cambridge: Cambridge University Press.

SCHOENBERG, Arnold. (1969). Structural Functions of Harmony. New York: W. W. Norton \& Company Press.

SHAKESPEARE, William (2000). Poemas de Amor. Trad. Bárbara Heliodora. Rio de Janeiro: Ediouro Publicações. 
PELOSO AUGUSTO, Paulo Roberto. (2016) Elgar: o enigma das variações. Per Musi. Ed. by Fausto Borém, Eduardo Rosse e Débora Borburema. Belo Horizonte: UFMG, n.35, p.147-178.

SIRMAN, Berk (2006). Developing Variations: An Analytical and Historical Perspective. Uppsala: Uppsala Universitet.

THE ELGAR SOCIETY. Disponível em < http://elgar.org/elgarsoc/> Acesso em: 17 jul. 2014.

TURNER, Patrick (1999). Elgar's 'Enigma' Variations - a Centenary Celebration. London: Thames Publishing.

YOUNG, Percy M (1973). Elgar: A Study of a Musician. Connecticut: Greenwood Press, Publishers.

YOUNG, Ondine (1996). Frei aber einsam, frei aber froh: cyphered motives and performance practice. Santa Cruz: University of California Press.

ZAMACOIS, Joaquin. (1983). Temas de Estética y de Historia de la Musica. Barcelona: Labor.

\section{Referências de partituras}

BACH, Johann Sebastian (1992). Kantate: Jesus nahm sich die Zwölfe BWV 22. Leipzig: Neue Bach-Ausgabe.

BEETHOVEN, Ludwig (1985). Streichquartett op. 135. Wien: Wiener Philharmonischer Verlag.

BRAHMS, Johannes (1862). Variationen über ein Thema von Händel, op.24. Leipzig: Breitkopf \& Härtel.

ELGAR, Edward. (1899) Variations on an Original Theme 'Enigma’ Op.36 (A Full Score). London: Masterson Press.

Nota sobre o autor

Paulo Roberto Peloso Augusto é Doutor em História Social pela Universidade de São Paulo (1996); Professor Titular da Escola de Música da Universidade Federal do Rio de Janeiro, atuando nos Departamentos de Composição e de Musicologia. 